\title{
CHANGES IN THE BUYING BEHAVIOUR OF THE COMPANIES WITHIN THE CONTEXT OF THE DIGITAL ENVIRONMENT
}

\author{
Mircea FUCIU \\ mircea.fuciu@ulbsibiu.ro \\ Andreea-Nicoleta DRAGOMIR \\ andreea.dragomir@ulbsibiu.ro \\ “LUCIAN BLAGA” UNIVERSITY, SIBIU, ROMANIA
}

\begin{abstract}
The social and business environments have changed greatly in the last two years, in the conditions of the COVID-19 pandemic and the condition of increased adoption of the digital based activities in the everyday lives of the company. New tools and activities, like "remote working", "online interaction", "video conferences" are just some of the new tools that have changed the Business-to-Business (B2B) marketing and buying behaviour landscape and made it jump from the traditional to the current and possibly the future approach. The current paper tracks some of the changes that have occurred in the Business-to-Business marketing environment, while underlining the effects he shift to digital has had on the business consumers and on their buying behaviour, being sustained by several secondary data analyses resulted from current reports, which are the basis for developing successful B2B marketing strategies and tactics.
\end{abstract}

\section{KEYWORDS:}

Business-to-business marketing, buying behaviour, changes, future, online environment

\section{Introduction}

Change is not new, but at the same time its effects and the rapid pace it produces modifications in the social and business environment are something companies, managers and the society at large must be aware of and also, they must take account when establishing their marketing strategies. While the companies are heading towards internationalization and towards globalization, the $21^{\text {st }}$ Century evolution of the business environment also has changed the focus of some companies by reverting to a more localized business approach, sometimes called the Glocal model (Hall, 2017).

At the same time, whether going local or going global, the companies' activity has strongly been affected by the increased need for data and information technologies, the need to capitalize on new technologies, to operate with the rapid shifting business models and the new behaviours within the companies. 
Of course, one must also consider the changes that are generated within the lives of the individual consumer, but also within the lives of the business consumers by the COVID-19 pandemic. While many authors usually deal with the changes of the Business to Consumer (B2C) consumer, it seems that the Business to Business (B2B) is not covered so much by the recent studies in the field, especially those that go over the changes generated by the new ICT-based business consumer behaviour.

In the last decade or so, and especially within the last years, the business environment has changed greatly with the extensive usage of social media, the usage of the online and digital environment to survive in the context of an ever-increasing global competition and in light of the new Covid-19 pandemic, companies have or must change the way they do business. According to Hall (2020), more than $76 \%$ B2B marketers feel that "marketing has changed more in the past two years than in the previous 50 years".

The current paper aims at providing insight into the new B2B marketing landscape, to present the concepts of consumer, consumer behaviour and industrial consumer behaviour, while showing the similarities and differences between the two, we are presenting the most important changes that have occurred in the $\mathrm{B} 2 \mathrm{~B}$ buying behaviour under the pressure of online environment development and under the pressure of the COVID-19 pandemic, while pointing out several statistics that support the changes and the perception that the B2B marketing landscape in general and the selling and buying behaviour will never be the same.

\section{A new business-to-business marketing landscape}

Connectivity or rather interconnectivity is probably the most important game changer in the history of the current marketing activity. The digital based connectivity has made a large number of theories and major assumptions that we have learned about reconsider the customer, the product and also the marketing management (Kotler et al., 2017).

Connectivity has also changed the way we approach the competition and especially the individual and business consumers. The consumers are no longer the inanimate receivers of messages, the targeting and positioning moves of one company. They are actual actors within the entire marketing process, by direct interaction and collaboration with the company and the business environment.

In the new business environment where communication is key, where digital interaction allows companies to communicate with their consumers from all over the world, there are many changes in the $\mathrm{B} 2 \mathrm{~B}$ landscape that need our attention (see Figure no. 1).

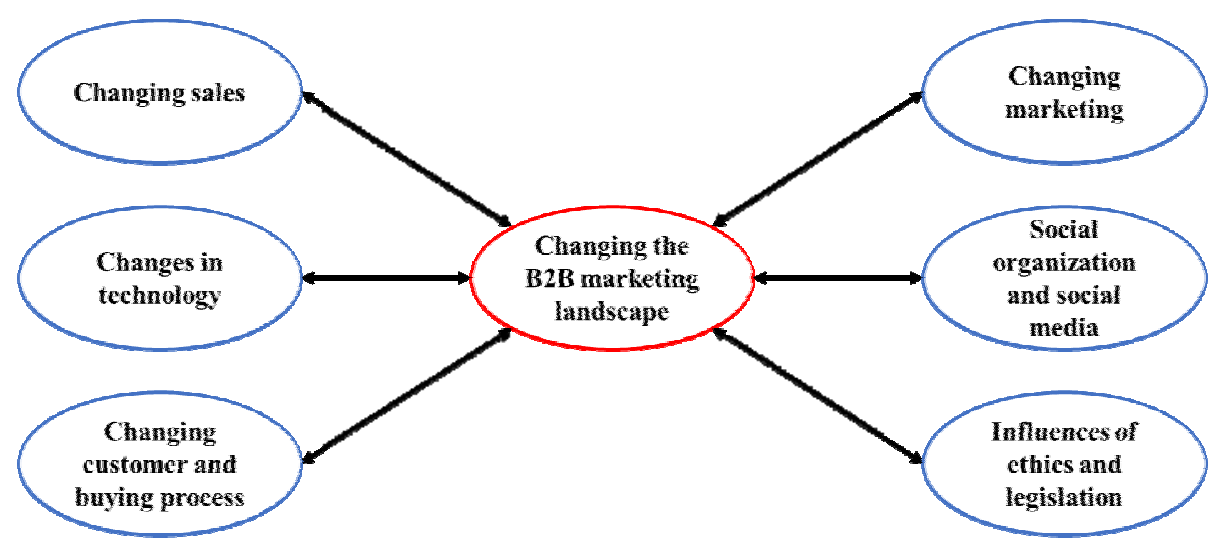

Figure no. 1: Changes in the B2B landscape

(Source: Hall, 2020, p. 2) 
From Figure no. 1, we can see the main areas of the Business-to-Business environment that are changing or that need to change to adapt to the new realities of the 21 st century. With an ever-increasing demand from the consumers, the marketing managers must understand how they interact and influence the current and potential clients and their buying process. At this time, we see the B2B specialists trying to reach customers, to nurture them and more than ever to improve their customer experience. The main changes that have occurred in the B2B environment, are acting upon the company and through it, upon the B2B consumers (Hall, 2020):

- Changing sales - the journey of the consumer (individual or business alike) has changed due to the need of nurturing leads and enabling sales, by improving content or generating it to meet the needs of the consumers and delivering the message through different communication channels (online and offline), and also ensuring message consistency (to meet the communication objectives of the companies).

- The new B2B consumer - in the context of a globalised economy, of the possibility to buy products or services from all over the world, and also with B2B customers that are more geographically distributed, the usage of new technologies, of collaborative software (ERP Systems) and virtual meets (like Zoom, Google meet, Teams) offer the company and the clients the possibility to meet face to face while being divided by great distances and not just that. Another aspect of the new 21st century B2B customer experience has also become an increasingly important topic for the digital marketers.

- Legislation and ethics - in the context of digitalisation and interconnectivity, a new need has arisen, the need for data protection and privacy, by the usage of policies like the GDPR (in the EU), or the Data Protection Act (in the UK), elements that force the companies to be more careful with the personal data of their individual or institutional consumers. Secondly, the ethical aspect is also taken, more and more, into account, due to the need of companies to apply a more socially responsible marketing, which can and must be of greater importance for the consumers.

- New technologies and their influence - artificial intelligence, response boots, personalised messages, smartphone (mobile phone) marketing, search engine optimisation (SEO), social media platforms, advanced analytics are just some of the new business environment tools and influence factors that generate personalised interaction with the B2B consumers, improve communication and influence the buying behaviour of the $\mathrm{B} 2 \mathrm{~B}$ clients.

\section{behaviour \\ 3. Business consumers and buying}

Discussing the issue of Business-toBusiness Marketing is not very different from the Business-to-Consumer one, and before we go further, we must underline the concept of consumer focusing on the definition given by the American Marketing Association (Ferris et al., 2010): "Depending on the firm's business, a customer might be defined as an individual, household, screenname, division, or business who bought, ordered, or registered a product", or "the actual or prospective purchaser of products or services" (AMA, 2014).

Other authors (Cătoiu \& Teodorescu, 2002; Florescu et al., 1992) define consumer behaviour as "all the decisional acts of the individual or of the group, directly linked to the obtaining and using of goods and services, with the purpose of satisfying the current and future needs, including the decision-making processes that precede and determine these acts".

Starting from these definitions, the next logical step is to present the process of buying behaviour. According to Kotler and Armstrong (2018), there are five main steps in the process of buying by the individual consumer, as seen in Figure no. 2. 


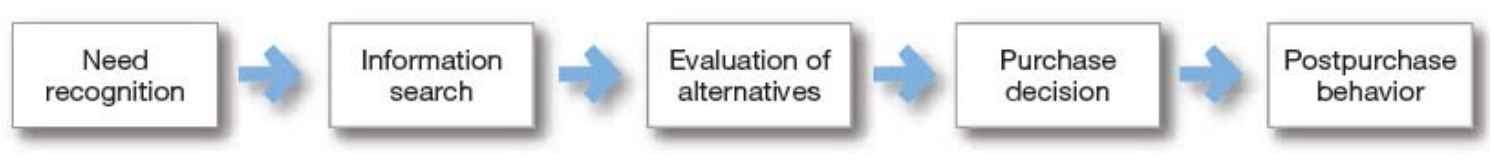

Figure no. 2: Individual consumer buying behaviour

(Source: Kotler \& Armstrong, 2018, p. 175)

On the other hand, the concept of $\mathrm{B} 2 \mathrm{~B}$ consumer buying behaviour is defined as: "the process of buying behaviour by which the organizations establish the acquisition need for products and services and identify, evaluate and choose form the existent alternative on the market" (Webster \& Wind, 1972). Also, the business buyer behaviour represents the intent and behaviour shown by companies and their employees into making purchases for the organization. Business buying behaviour is the concept of understanding the needs and wants of a business and making appropriate purchases, which ultimately help a company get profits.
Kotler (Kotler \& Armstrong, 2018) defines the business buyer behaviour as: "the buying behaviour of organizations that buy goods and services for use in the production of other products and services that are sold, rented, or supplied to others". The business buying process is "the decision process by which business buyers determine which products and services their organizations need to purchase and then find, evaluate, and choose among alternative suppliers and brands" (Kotler \& Armstrong, 2018). The main structure of the business buying behaviour can be seen in Figure no. 3.

\begin{tabular}{|c|c|}
\hline \multicolumn{2}{|c|}{ The environment } \\
\hline $\begin{array}{c}\text { Marketing } \\
\text { stimuli }\end{array}$ & $\begin{array}{c}\text { Other } \\
\text { stimuli }\end{array}$ \\
Product & Economic \\
Price & Technological \\
Place & Political \\
Promotion & Cultural \\
& Competitive \\
& \\
\hline
\end{tabular}

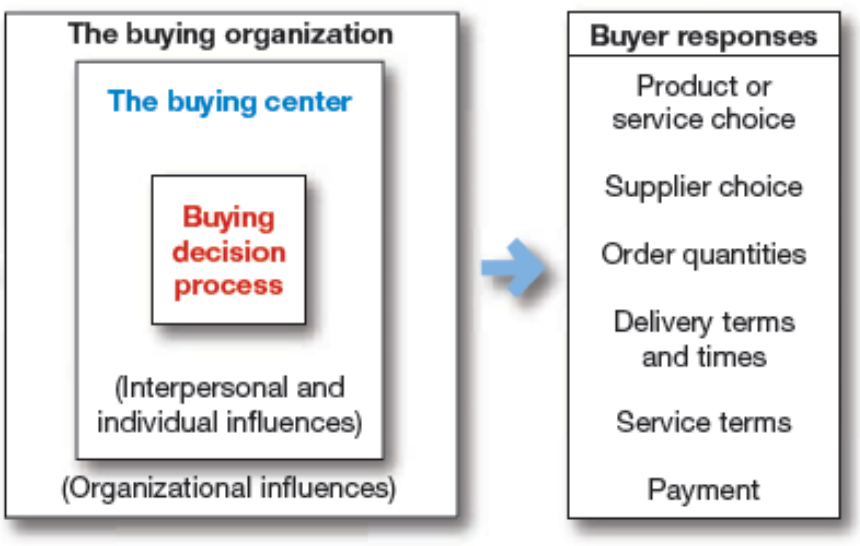

Figure no. 3: Business buying behaviour model

(Source: Kotler \& Armstrong, 2018, p. 191)

At the same time, Hall (2020, pp. 3536) maintains the idea that the business buyer behaviour is similar with the individual buyer behaviour with 5 main steps, such as: need recognition, need quantification, vendor review, purchase, and post purchase behaviour. Considering the slight differences between the two approaches, the need quantification refers to the need to identify and gain the consent for the acquisition of a product that fulfils the need. The vendor review covers the information search and vendor search that could fulfil the needs of the company.

The biggest difference between the individual consumers and business consumers is generated by the types of buyers that act within the buying process. In the $\mathrm{B} 2 \mathrm{~B}$ sector, the main actors are (Kotler \& Armstrong, 2018; Hall, 2020; Ryan 2013): 
- Users are members of the organization who will use the product or service. In many cases, users initiate the buying proposal and help define product specifications.

- Influencers often help define specifications and also provide information for evaluating alternatives. Technical personnel are particularly important influencers.

- Buyers have formal authority to select the supplier and arrange terms of purchase. Buyers may help shape product specifications, but their major role is in selecting vendors and negotiating. In more complex purchases, buyers might include high-level officers participating in the negotiations.

- Deciders have formal or informal power to select or approve the final suppliers. In routine buying, the buyers are often the deciders, or at least the approvers.

- Gatekeepers control the flow of information to others. For example, purchasing agents often have authority to prevent salespersons from seeing users or deciders. Other gatekeepers include technical personnel and even personal secretaries.

\section{Changes of the buying behaviour}

Due to the complexity of the business buying behaviour, there are other elements that the $21^{\text {st }}$ century company must be aware of and also use in order to achieve success. Among the most important aspects that one should consider when developing their marketing strategy in conjunction with the components of the marketing mix (and their policies), we might consider (Penn, 2021):

(a) a longer buying cycle - when discussing the $\mathrm{B} 2 \mathrm{~B}$ decision making process, we must account for the longer buying cycle compared to the consumer ore. Why? Simply because there are more steps involved and the level of involvement that is needed is more consistent.

(b) the process is based on the desires and fears of the buyer - in a B2B context, the buyer's fears, on the one hand, the loss of business to the competitors, but on the other hand, there is the desire to succeed, to make profit and to secure the future. In a context of changing markets, these aspects become more pronounced and should lead to immediate action.

According to Forrester (Caplow, 2021), there are three main changes that have occurred in the B2B buying behaviour during the pandemic and in the context of an ever-increasing need for digitalisation of the business:

(a) the word buyers, implies now a buying group - in the condition of remote working, the buying status of independent action has shifted to a group of buyers that are now involved. Forrester's report shows that in $2021,63 \%$ of purchases have more than four people involved vs. just $47 \%$ in 2017 and they can include different buyer roles: champions, influencers, decision makers, users, or ratifiers, from multiple departments.

(b) increase in buying interactions if before, the number of interactions between the business consumer and the company was lower, due to the changes generated by the pandemic, these interactions have now increased tenfold. The interactions reflect the journey of the buyer to get the information about offers and main providers, one of the main causes being the extensive usage of the online environment as well as personal interactions (using the online communication platforms).

(c) the buyers rely on the internet to get information - with high internet accessibility and large content availability from the providers of the industry, the buyers can find almost every information about the $\mathrm{B} 2 \mathrm{~B}$ products or services that they are interested in anytime and anywhere. Access to online webinars, forums, online events can offer insight into new and innovative products that can provide value in the context of an 
everchanging and growing global competition in the world of B2B.

But the complexity of the changes in the $\mathrm{B} 2 \mathrm{~B}$ area is not just what we presented above, but it is also generated in the context of the online environment by other aspects like (Sadasivan, 2021):

(a) time to job completion - if before, job completion represented closing the deal on the acquisition, today, job completion means progress in their purchase process, because the changes in the business environment no longer follows the linearsupplier-centric sales funnel.

(b) no more "handoff" - before the explosion of the online, handoffs were common in the face-to-face meetings and deals of the B2B, nowadays, the online environment changed this and they use equal digital and in-person channels to simply complete their B2B buying jobs.

(c) influencing the business consumers is fast business - due to the complexity and large presence of $\mathrm{B} 2 \mathrm{~B}$ suppliers from all over the world, the providers only have brief windows of opportunities to influence the decisionmaking process. Usually, now the suppliers should take on the role of guides - to help B2B customers to navigate the business buying process and to use their insight to help the consumers avoid obstacles they did not foresee.

(d) the dynamics in the seller activity has changed - sales agents are not the only channels for the consumers to find information, but one of the channels, and the alignment of in-person and digital channels has become crucial for sales representatives to support their customers and finalize the acquisition.

Of course these changes have also generated behavioural modification in the ways the business consumers act in the process of buying B2B based products. A recent McKinsey and Co. report (BagesArmat et al., 2020) shows these behavioural changes in the figures bellow.

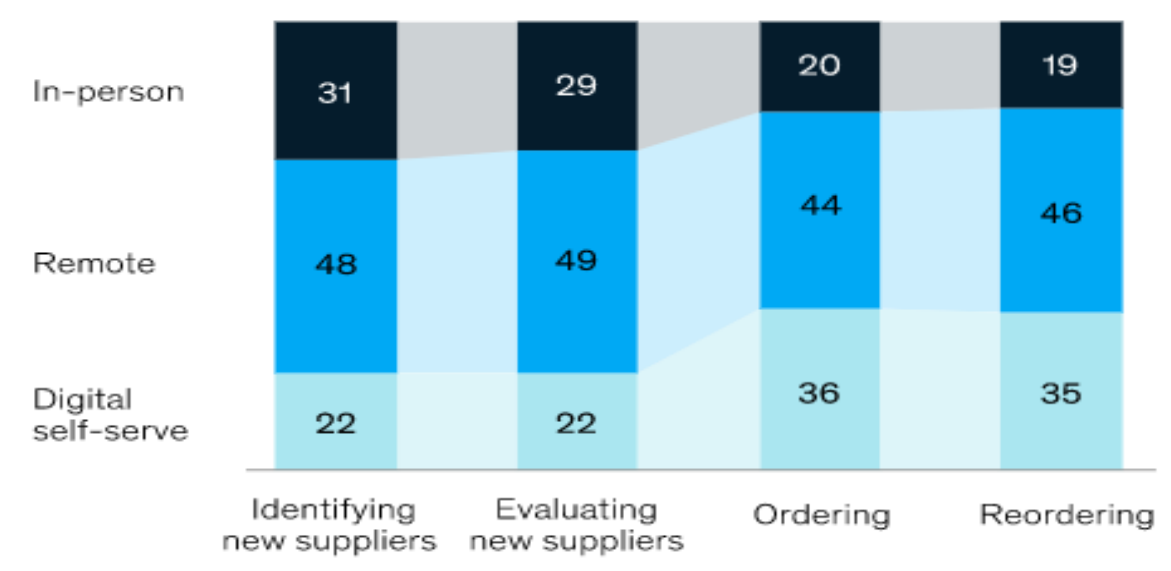

Figure no. 4: B2B interaction with suppliers in different stages of the process

(Source: Bages-Armat et al., 2020)

In Figure no. 4, we can see that for all the four stages the remote method of interacting with the sellers represents the majority, the highest being for the evaluation of new suppliers - $49 \%$, and the lowest was for ordering - $44 \%$. The change towards the digital and remote engagement has been largely used by decision makers in the great majority of markets.

When asked if the new digital model of interaction is effective in interacting with consumers, in the case of the countries that have taken part in the McKinsey survey, the responses can be seen in Figure no. 5. 


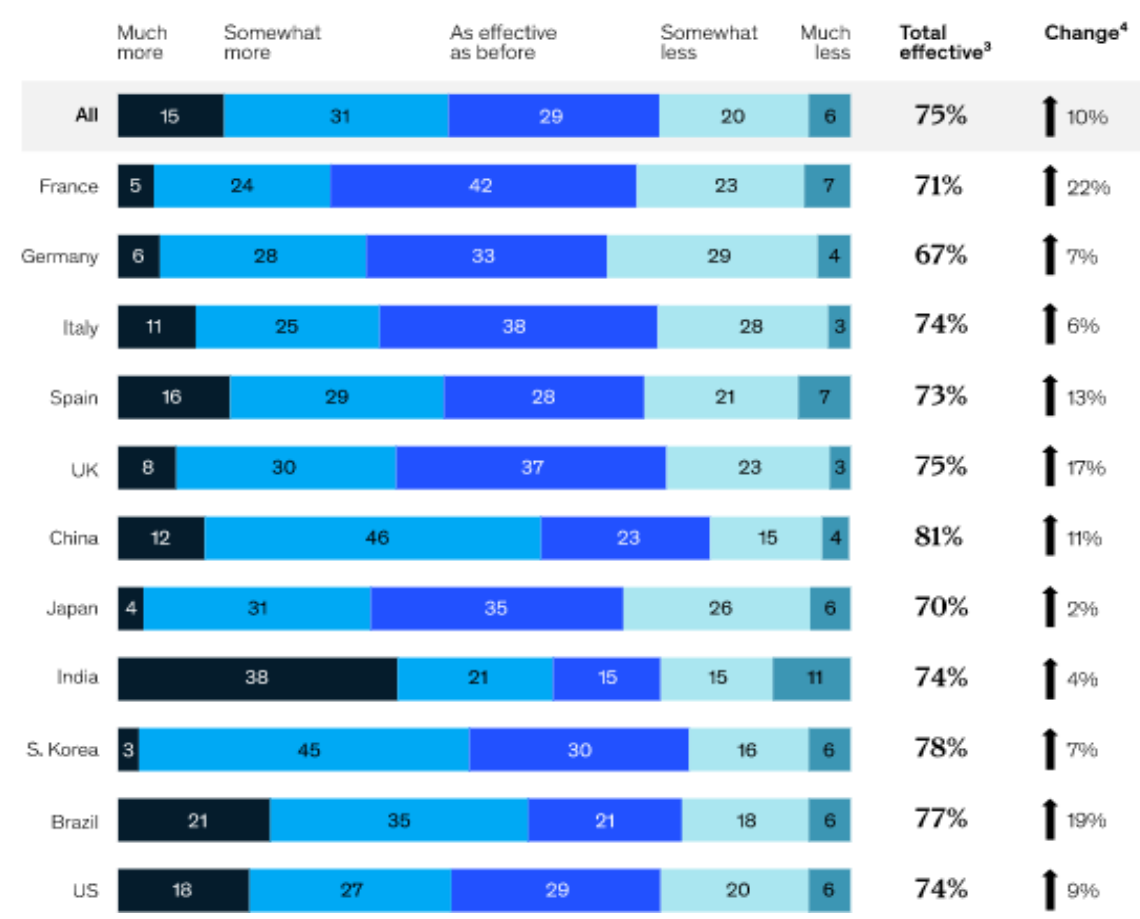

Figure no. 5: Effectiveness of the new methods of interaction with the consumers

(Source: Bages-Armat et al., 2020)

As we can see in Figure no. 5, the country with the highest online interaction is e China with $84 \%$ effectiveness, and a $11 \%$ increase, followed by South Korea $78 \%$, Brazil - $77 \%$, the United Kingdom $75 \%$ and Italy - $74 \%$. The lowest effectiveness can be seen in the case of Germany with a $67 \%$ overall effectiveness and a $7 \%$ change from the previous survey. The overall average percentage of effectiveness is at $75 \%$. But we have to acknowledge that the survey did not have a linear number of respondents and for this

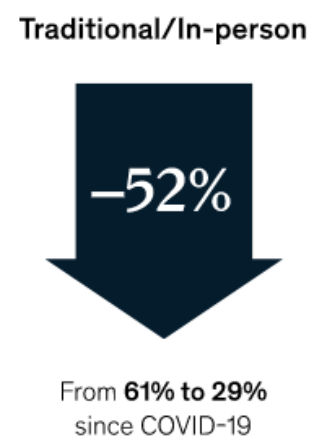

question the distribution varied between 200 and 600 respondents per country.

Among the biggest game changers in the current $\mathrm{B} 2 \mathrm{~B}$ marketing environment the COVID-19 pandemic is probably the strongest, and it forced the companies to go digital. Therefore, it also stimulated the consumers to become more interactive and use the digital environment more in the B2B buying process. In Figure no. 6 we can see how the consumers have changed their approach to sales interaction before and after the COVID-19 pandemic.

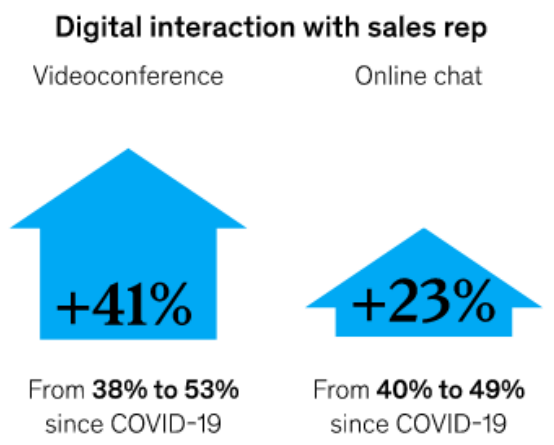

Figure no. 6: Sales interaction channels before and after the COVID-19 pandemic

(Source: Bages-Armat et al., 2020) 
We can observe a huge decrease $(52 \%)$ in the traditional interaction method and also a high increase in using digital based communication channels, a $41 \%$ increase for videoconferences and a $23 \%$ increase for online chatting with $\mathrm{B} 2 \mathrm{~B}$ consumers. Of course, when asked about the utility of the platforms used to interact with the B2B consumers, the results can be seen in Figure no. 7.

- More helpful Neutral
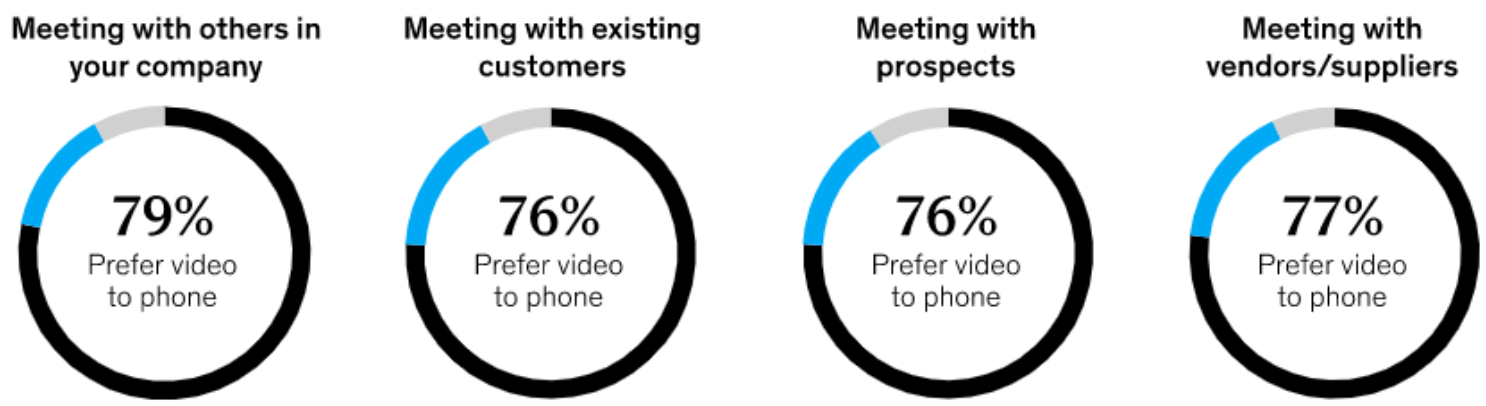

Figure no. 7: Utility of the video platforms vs. phone interactions related to different activities of $B 2 B$

(Source: Bages-Armat et al., 2020)

As one can see in Figure no. 7, all the repsondents seem to have a preferance for video rather than classical phone interaction, with $79 \%$ of the respondents stating that they prefer video over phone for meetings with collegues, $77 \%$ for meetings with suppliers and $76 \%$ for meeting with current and potentioal B2B consumers.
But how will the trend evolve in the future? When asked if they consider that in the next period of time (more than 12 months) they will continue to use these methods and platforms, the responses changed from the Aprill 2020 panel responses to the August 2020 panel responses as seen in Figure no. 8.

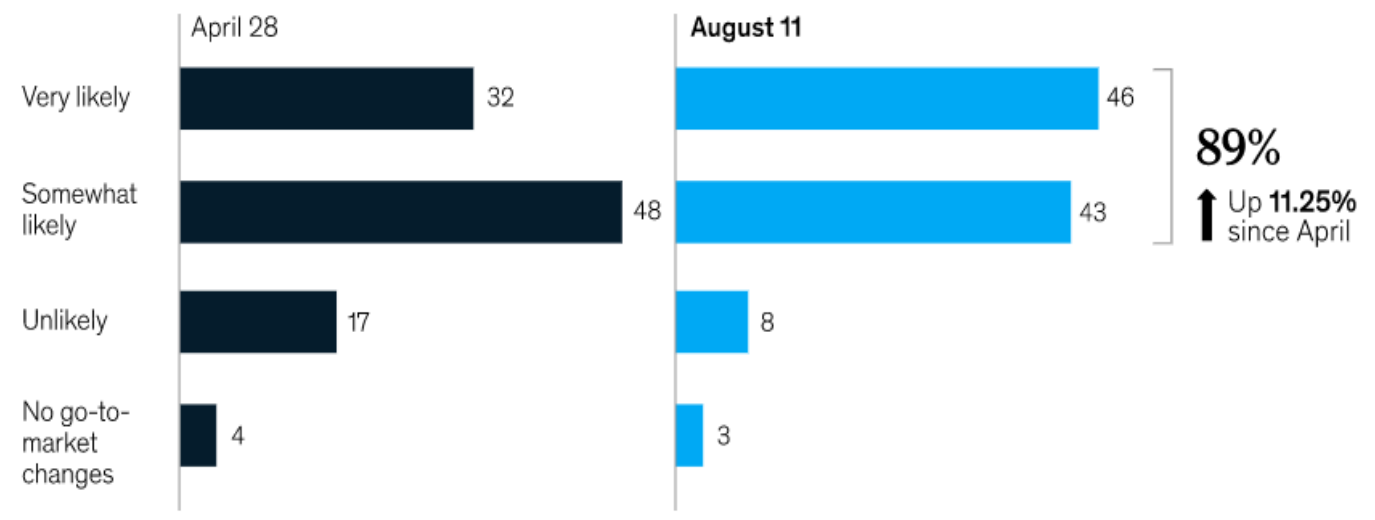

Figure no. 8: April vs. August 2020 perception of usage of the new interaction methods in B2B (Source: Bages-Armat et al., 2020)

Seeing the results in Figure no. 8, we can observe that there is an overall $11.25 \%$ increase in the perception that the methods will be used in the next year or so, with an increase from $32 \%$ to $46 \%$ for very likely, a decrease from $48 \%$ to $43 \%$ in somewhat likely. 
A different analysis of McKinsey and Co. (Harrison et al., 2020), shows the results of a survey developed on 3600 B2B decision makers over 11 countries and 12 business sectors, which point out the rapid changes of the $\mathrm{B} 2 \mathrm{~B}$ sector and of the buying behaviour, as follows:

(a) the average shift from traditional to online interactions has increased two times (three times in Spain and UK);

(b) 30 of the B2B consumers increase their preference for placing orders on mobile apps.

(c) there is an increase of $250 \%$ for downloading mobile app ordering.

(d) $96 \%$ of the B2B teams have shifted to the online and remote selling.

(e) $65 \%$ of the B2B decision makers are stating that remote selling is "the same if not more effective" than traditional.

As we can see changes and shifts are happening and they are strongly impacting the company, the consumers and the $\mathrm{B} 2 \mathrm{~B}$ decision making process. Changes in the life cycle, in the buying processes itself, in the methods of selling and interacting with the intended target, combined with the changed needs of the consumers seem to be the new norm that should be a starting point for developing new B2B market strategies.

\section{Conclusions}

The shift of the business environment towards the digital and the online is normal and also represents the future for the 21 st century companies. While the Covid-19 pandemic has become a powerful catalyst for going digital, it is not by all means the only change factor that has occurred.

While the scientific literature makes a clear distinction between the individual consumer and the business consumer, and also between the classic consumer behaviour and the B2B business buying behaviour, as presented in the previous sections of the paper, the new business conditions generated by the pandemic, and by the shift towards the digital engagement of the consumers, the B2B buying and selling behaviour jumped leaps and bounds to change from the traditional to the current status.

In the current paper we have presented a brief revision of the concepts and models related the B2B consumers and buying behaviour tackled in the specialized literature, but also, as well as some of the changes that occurred in the industry in the last year or so, by underlining several results of secondary data analyses developed in the field, to support the theoretical findings. All in all, we can safely conclude that the B2B environment and its sales and buying behaviour are changing and it seems that there is no going back.

We are witnessing accelerated digital transformation initiatives of the B2B companies, there are changes in the budget of the companies that are specific to technological implementation and development, global / international competition accessible online that have created the premises for swiftly and effectively changing suppliers. They also use their own personal experience, the previous B2B experience when identifying market opportunities using the information available online - specialised webinars, online websites, social media etc.

The future of the B2B buying behaviour and of the field shows that if the companies want to be successful and desire to be able to face the threats that are coming from the ever-increasing competition, they must develop B2B marketing strategies that are aimed at the continuation of the digital transformation, strategies that develop value not just deliver advertising (B2B consumers are no longer interested in it), strategies that will help companies implement some form of artificial intelligence or automated systems to make their activity more efficient and develop communication strategies that are combining the usage of professional social media platforms (Cartwright et al., 2021), influencer marketing and personalised direct mailing. 


\section{REFERENCES}

American Marketing Association, AMA Dictionary: Customer. (April 2014). Available at: https://marketing-dictionary.org/c/customer/, accessed on 28 October 2021.

Bages-Armat, A., Harrison, L., Spillecke, D., \& Stanley J. (2020). These eight charts show how COVID-19 has changed B2B sales forever. McKinsey and Company, available at: https://www.mckinsey.com/business-functions/marketing-and-sales/our-insights/these-eightcharts-show-how-covid-19-has-changed-b2b-sales-forever, accessed on 29 October 2021.

Caplow, B. (2021). Three Seismic Shifts in Buying Behaviour from Forrester's 2021 B2B Buying Study. Available at: https://www.forrester.com/blogs/three-seismic-shifts-inbuying-behavior-from-forresters-2021-b2b-buying-survey/, accessed on 29 October 2021.

Cartwright, S., Liu, H., \& Raddats, C. (2021). Strategic use of social media within business-to-business (B2B) marketing: A systematic literature review. Industrial Marketing Management, Vol. 97, 35-58

Cătoiu, I., \& Teodorescu, N. (2002). Consumer Behaviour. Bucharest: Uranus Publishing House, 13.

Farris, P.W., Neil, T.B., Pfeifer, Ph.E., \& Reibstein, D.J. (2010). Marketing Metrics: The Definitive Guide to Measuring Marketing Performance ( $2^{\text {nd }}$ Edition). Upper Saddle River, New Jersey: Pearson Education, Inc.

Florescu, C. (1992). Marketing. Bucharest: ASE Publishing House.

Hall, S. (2017). Innovative Business to Business marketing - new models, processes and theory. London, UK: Kogan Page.

Hall, S. (2020). B2B digital marketing strategies - how to use new frameworks and models to achieve growth. London, UK: Kogan Page.

Harrison, L., Gavin, R., Plotkin, C.L., \& Stanley, J. (2020). How B2B sales have changed during COVID-19. McKinsey and Company, available at: https://www.mckinsey.com/business-functions/marketing-and-sales/our-insights/how-b2bsales-have-changed-during-covid-19, accessed on 30 October 2021.

Kotler, P., Armstrong, G., \& Opresnik, M.O. (2018). Principles of Marketing $\left(17^{\text {th }}\right.$ Edition). Pearson Education.

Kotler, P., Kartajaya, H., \& Setiawan, I. (2017). Marketing 4.0 - moving from traditional to digital. New Jersey, USA: Wiley and Sons, Hoboken.

Penn, S. (2021). B2B buyer behaviour is shifting - How B2B Marketers must adapt. Available at: https://www.g2msolutions.com.au/blog/bid/110308/B2B-buyer-behaviour-isshifting-How-B2B-Marketers-must-adapt, accessed on 29 October 2021.

Ryan, C. (2013). Winning B2B Marketing. Colorado Springs, USA: Fusion Marketing Press.

Sadasivan, S. (2021). Straight line to concentric circles - The complex world of B2B buying in 2021. Available at: https://www.b2bmarketing.net/en-gb/resources/blog/straightline-concentric-circles-complex-world-b2b-buying-2021, accessed on 30 October 2021.

Webster, F.E., \& Wind, Y. (1972). A general model for understanding organizational buying behaviour. Journal of Marketing, Vol. 36, Issue 2, 12-19. https://doi.org/10.2307/1250972 